\title{
Implications of the Covid-19 Pandemic for Economic and Demographic Research
}

Frank-Borge Wietzke

Follow this and additional works at: https://knowledgecommons.popcouncil.org/series_pdr_essays-covid How does access to this work benefit you? Let us know!

\section{Recommended Citation}

Wietzke, Frank-Borge. "Implications of the Covid-19 Pandemic for Economic and Demographic Research." In Covid-19 and the Global Demographic Research Agenda, edited by Landis MacKellar and Rachel Friedman, 73-76. New York: Population Council, 2021. 


\title{
Implications of the Covid-19 \\ Pandemic for Economic and \\ Demographic Research
}

\author{
FRANK-BORGE WIETZKE
}

\begin{abstract}
AS WE ARE ENTERING the second or even third wave of Covid-19 infections, much research is still needed to assess the true global health impacts and death toll of the pandemic. This applies in particular to low- and middle-income countries, where testing and diagnostic capacities are still often rudimentary. What we can say with certainty is that the economic consequences of Covid-19 are dramatic. This note therefore concentrates on the socioeconomic dimensions of the pandemic, and specifically their possible interactions with demographic behaviors. I focus on developing regions, where populations are often most heavily affected.
\end{abstract}

\section{Covid-19: A Magnifier of Preexisting Weaknesses and Vulnerabilities}

Across the global South, preventive and containment measures have disrupted labor and product markets and imposed high economic costs on the local population. This was accompanied by rapidly contracting fiscal space, as governments scrambled to mobilize scarce resources for (often piecemeal) emergency interventions. The magnitude and consequences of these developments cannot be understated. At the global level, the Covid-19 pandemic has reversed previous trends toward diminishing between-country inequalities, as capacities for effective monetary and fiscal responses diverge sharply between the developed and developing world. Within developing countries (as well as developed ones), the pandemic has accelerated widening income gaps and social disparities among the population. ${ }^{1}$

Covid hit low- and middle-income nations at a time when-despite often rapid growth and poverty reduction over the past decades-the situation for vast parts of the population was still precarious. Global poverty at the "extreme" purchasing power-adjusted $\$ 1.90$ poverty line stood at an estimated 9.2 percent before the pandemic. However, this disguised important variation between countries and regions. In less-developed continents like sub-Saharan Africa, national extreme poverty head counts averaged 40 percent and absolute numbers

Frank-Borge Wietzke, Institut Barcelona d'Estudis Internacionals and European University Institute. 
of extreme poor were either stagnant or declining only slowly, once changes in underlying population sizes were taken into account (World Bank 2020). ${ }^{2}$ In addition, tens of millions of those who had escaped poverty were still in economically insecure circumstances. Even small idiosyncratic shocks, such as a short-term loss in income or a health emergency, could push these households back into extreme poverty (López-Calva and Ortiz-Juarez 2014).

These shocks have, of course, been magnified and generalized by the pandemic. In many developing countries, lockdown measures and economic contraction have deprived especially those in informal or precarious forms of employment of their main sources of income. By some estimates, these effects could raise the global poverty head count at the $\$ 1.90$ poverty line by up to 6 percentage points (Sumner, Hoy, and Ortiz-Juarez 2020). This situation was only partially mitigated by government interventions. Although many countries put in place social assistance programs, these were often short-term and accompanied by reduced access to basic services, as lockdowns limited users' ability to reach facilities. Large-scale debt relief or rapid increases in development assistance withstanding, we should expect government responses to contract further, as public budgets in many emerging economies remain under severe stress. ${ }^{3}$

\section{Consequences for Demographic Research}

What are the implications for demographic research? We know from previous studies that, individually, households' coping strategies can affect various parameters that matter to demographic outcomes and reproductive behavior, such as reductions in spending on health care, contraceptives, or girls' education (Skoufias 2003). These economic adjustments are magnified by the social costs and gendered impacts of the pandemic itself. During the Covid-19 crisis-as in previous years - women bear most of the responsibility for childcare, elder care, and housework, while simultaneously providing the bulk of the workforce in the local public health response (Cousins 2020; Hall et al. 2020).

Simultaneously, lockdown measures and increased financial pressures on governments and charities have disrupted access to women's sexual and reproductive health and prenatal and postnatal care. Experiences with past humanitarian crises have shown that such sudden disruptions to health supply can result in growing rates of unintended pregnancies, increased child and infant mortality, as well as a broad range of other reproductive and mental health problems (McGinn 2000).

These widespread shocks may undo decades of progress in advancing gender equality, reproductive health, or even the structural shift toward lower fertility in many developing countries. Learning about the extent of these problems, as well as the appropriate policy responses, will require more integrated research at the interface of economics and social demography. I focus here on three interlinked questions.

First, as long as evidence about the on-the-ground health and economic impacts of the crisis remains patchy in many countries, more systematic analysis will be needed to determine which populations and subgroups were most 
affected. These assessments should be based on more robust and representative data sources than were so far (typically) available during the pandemic, and pay particular attention to interactions between household coping responses and impacts on gender, health, and demographic outcomes, as described above.

Second, and adopting a longer-term view, more research is needed to study effects of deteriorating gender and socioeconomic indicators on household- and group-specific fertility outcomes. The purpose of this analysis would be to identify possible divergence in reproductive behaviors that could point to delayed or even reversed fertility transitions for countries or parts of the population. Useful templates would be provided by previous disaggregated research that tried to identify population- or subgroup-specific drivers of lower-than-average fertility reductions in developing regions like sub-Saharan Africa or Latin America (Bongaarts and Casterline 2013; Bongaarts 2017; Rios-Neto, Miranda-Ribeiro, and Miranda-Ribeiro 2018; Wietzke 2020).

Finally, the particular nature of the crisis should be recognized as an opportunity to question some of the more established indicators and subgroup classifications that are often used to proxy for socioeconomic contexts in the analysis of local demographic behaviors. For example, while the validity of binary urbanrural classifiers was already put in question by the rapid growth of intermediary peri-urban areas in many developing regions (Mbiba and Huchzermeyer 2002; Karg et al. 2019), the use of rural identifiers as a stand-in for generalized socioeconomic disadvantage has come under further scrutiny, as impacts of the crisis are often concentrated among urban populations (World Bank 2020). Future changes in lifestyles and production patterns while countries move through the crisis and into recovery may require further reconsideration of these categories.

Where will the data for these analyses come from? In the medium- to long-term, the bulk of systematic and representative studies of Covid-19 impacts will be provided by the usual sources, such as government statistics, population censuses, or nationally representative household surveys. However, these typically arrive with long time lags and at infrequent intervals and may be further delayed by local responses to the pandemic. It is thus unlikely that they will allow particularly up-to-date or fine-grained over-time analysis of Covid-19 impacts in the near future.

In these contexts, it may be necessary to also think about possible alternative data sources. For instance, in the field of economic poverty and vulnerability analysis, researchers often rely on high-frequency telephone surveys to track the effects of Covid-19 and previous economic crises. These often include rudimentary modules on health and demographic behaviors (or could be enriched by such modules), that would permit more up-to-date analysis of the crisis impacts in areas of interest to demographers. ${ }^{4}$

Regardless of the actual tools used, new pragmatic and often-interdisciplinary approaches will be needed to better understand the evolution of socioeconomic inequalities and demographic responses, as societies move through, and hopefully eventually emerge from, the pandemic. 


\section{Acknowledgments}

Research supporting this essay was funded by the Spanish Ministry of Economy, Industry, and Competitiveness (MINECO) through its Academic Excellence and Societal Challenges initiative (Grant Number CSO2017-87350-P).

\section{Notes}

1 https://www.wider.unu.edu/publication/five-ways-coronavirus-deepening-globalinequality. Last accessed August 1 1, 2020.

2 Estimates are for 2017 and adjusted for local purchasing power differences.

3 https://www.imf.org/en/Publications/ GFSR/Issues/2020/10/13/global-financial- stability-report-october-2020. Last accessed August 11, 2020.

4 See, for example, https://www.worldbank.org/en/topic/poverty/brief/high-frequency-monitoring-surveys. Last accessed August 11, 2020. Dabalen et al. 2016.

\section{References}

Bongaarts, John. 2017. "Africa's unique fertility transition," Population and Development Review 43(S1): 39-58.

Bongaarts, John and John Casterline. 2013. "Fertility transition: Is sub-Saharan Africa different?" Population and Development Review 38(Suppl. 1): 153-168.

Cousins, Sophie. 2020. "COVID-19 has 'devastating' effect on women and girls," The Lancet 396(10247): 301-302.

Dabalen, Andrew, Alvin Etang, Johannes Hoogeveen, Elvis Mushi, Youdi Schipper, and Johannes von Engelhardt. 2016. Mobile Phone Panel Surveys in Developing Countries: A Practical Guide for Microdata Collection. Washington, DC: World Bank.

Hall, Kelli Stidham et al. 2020. "Centring sexual and reproductive health and justice in the global COVID-19 response," The Lancet 395(10231): 1175-1177.

Karg, Hanna et al. 2019. "Classifying and mapping periurban areas of rapidly growing mediumsized sub-Saharan African cities: A multi-method approach applied to Tamale, Ghana," Land 8(3): 40 .

López-Calva, Luis F. and Eduardo Ortiz-Juarez. 2014. “A vulnerability approach to the definition of the middle class," Journal of Economic Inequality 12: 23-47.

Mbiba, Beacon and Marie Huchzermeyer. 2002. "Contentious development: Peri-urban studies in sub-Saharan Africa," Progress in Development Studies 2(2): 113-131.

McGinn, Therese. 2000. "Reproductive health of war-affected populations: What do we know?" International Family Planning Perspectives 26(4): 174-180.

Rios-Neto, Eduardo L.G., Adriana Miranda-Ribeiro, and Paula Miranda-Ribeiro. 2018. "Fertility differentials by education in Brazil: From the conclusion of fertility to the onset of postponement transition," Population and Development Review 44(3): 489-517.

Skoufias, Emmanuel. 2003. "Economic crises and natural disasters: Coping strategies and policy implications," World Development 31(7): 1087-1102.

Sumner, Andy, Chris Hoy, and Eduardo Ortiz-Juarez. 2020.. "Estimates of the impact of COVID-19 on global poverty." Working paper. United Nations University World Institute for Development Economics Research, Helsinki.

Wietzke, Frank-Borge. 2020. "Poverty, inequality, and fertility: The contribution of demographic change to global poverty reduction," Population and Development Review 46(1): 65-99.

World Bank. 2020. Poverty and Shared Prosperity 2020: Reversals of Fortune. Washington DC: World Bank. 